九州大学学術情報リポジトリ

Kyushu University Institutional Repository

\title{
Study of Evaluation Method of the Effect on the Presevation of Ecosystem by the Land Use Condition of Paddy Field
}

Anan, Mitsumasa

Takasaki Sogo Consultant Co., Ltd.

Yuge, Kozue

Department of Bioproduction and Bioenvironmental Sciences, Faculty of Agriculture, Kyushu University

Ohi ra, Yutaka

Kyushu Environmental Evaluation Association

Nakano, Yoshisuke

Emeritus Professor of Kyushu University

https://doi.org/10.5109/10096

出版情報: 九州大学大学院農学研究院紀要. 53 (1)，pp.221-225，2008-02-28. Faculty of Agriculture, Kyushu University

バージョン：

権利関係 : 


\title{
Study of Evaluation Method of the Effect on the Preservation of Ecosystem by the Land Use Condition of Paddy Field
}

\author{
Mitsumasa ANAN ${ }^{1}$, Kozue YUGE*, Yutaka OOHIRA ${ }^{2}$ \\ and Yoshisuke NAKANO ${ }^{3}$
}

\author{
Laboratory of Irrigation and Water Utilization, Division of Regional Environment Science, \\ Department of Bioproduction Environmental Sciences, Faculty of Agriculture, \\ Kyushu University, Fukuoka 812-8581, Japan \\ (Received November 9, 2007 and accepted November 30, 2007)
}

\begin{abstract}
The objective of this study is evaluating the effect of the land use condition on the ecological system in the rural area. The field observation was conducted in a 600 ha study site, which is located on the left bank of the Chikugo River in Kyushu Island, Japan. The living thing and ecosystem were investigated in a paddy field, rotated field, and ponded fallow field located in the study site.

In the ponded fallow field, many kinds of the living things, including the primary and secondary consumers, can be observed, comparing with in the rotated field, and the food pyramid is formed. The observation result showed that the ponded fallow field had a function very high as a habitat of living things.

From the land use condition map, the behavior range of the little egret in the object area is predicted. It was expected that the behavior range area of a little egret is divided, because there was no place used as a relay base of movement between western ponded fallow fields. Moreover, zoning for forming an ecological corridor in the study area was performed using this technique.

The numerical model about biodiversity was calculated from results of the investigation, and the land use condition which multifunctionality can demonstrate effectively was analyzed. Furthermore, the correlation diagram of multifunctionality and the land use condition of the paddy field was presumed. It becomes a leading technique to evaluate multifunctionality synthetically and create a correlation diagram, when deciding upon a rural land use plan.
\end{abstract}

\section{INTRODUCTION}

The paddy field and the agricultural irrigation canal network have many-sided functions other than an agricultural function, such as a life function, disaster prevention function, environmental preservation function, ecological function, and scene function, and it has existed, closing to the nature of the area and a life of residents for many years. However, the fallow field which nothing grows is increasing in recent years from the increase in a part-time farm household and the shortage of a successor of agriculture. The farmland which did not cultivate for several years is increasing, and it has been an important subject on farmland preservation. On the other hands, the custom which fills water in a fallow field is in rural society. Although filling water is uniquely carried out by the farmer for the maintenance of the field, such as weeds control, it is also expected that the habitat of various living things will be formed there. It is thought that water is an important element as a habitat of living things. Therefore it is a very important point on ecosystem formation whether field is ponded.

In this study, it takes notice of the form of use of a paddy field, and the relation of ecosystem preservation, and the habitation situation of the living thing in a paddy area was investigated. The study site is flat paddy field division, which is located on the left bank of the Chikugo

1 Takasaki Sogo Consultant Co., Ltd.

Kyushu Environmental Evaluation Association

Emeritus Professor of Kyushu University

* Corresponding author (E-mail: yuge@bpes.kyushu-u.ac.jp)
River in Kyushu Island, Japan (Fig. 1). In this area, paddy field are operated orthopedically, and the irrigation and drainage canals are separated completely (Anan et al., 2004), by which the farm land consolidation was

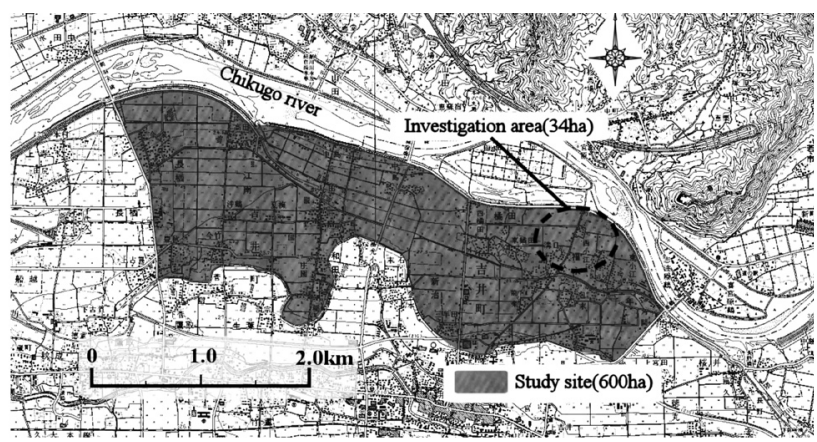

Fig. 1. The place of the study site.

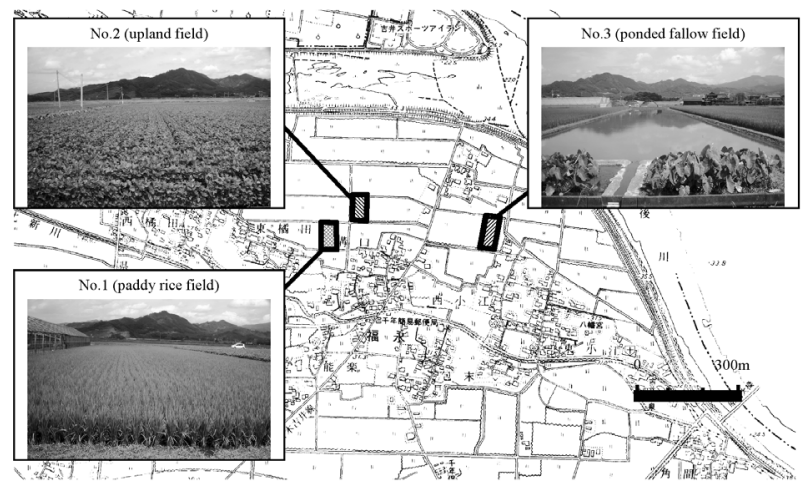

Fig. 2. Location of the investigation fields. 
undertaken since 1980. Although the paddy rice was grown in almost all paddy fields those days, also of flowering trees and a fruit tree besides soybeans is grown as rotational crops now. In order to investigate an ecosystem, three fields which are the usual paddy field, the upland field and the ponded fallow field were selected from the study site. Each field situation is shown in Fig. 2. From the results of an investigation of the ecosystem in each field, the land use condition verified about the influence on the habitat distribution.

\section{MATERIALS AND METHOD}

\section{Investigation of a land use situation}

In order to grasp the related characteristic of distribution of an ecosystem, and the land use situation, planted crops and a land use condition were checked by local exploration. The land use condition map was created from results of an investigation, and the planting area and ratio were measured.

\section{Investigation of an ecosystem}

The ecosystem was investigated in the same time zone of the day about three objective fields. In order to investigate habitation of the large living things of a moving range, and a flying situation, the fixed point observation was made on the field end, and watched calmly. The fixed point observation carried out for three minutes three times, and counted the living thing kind, the flying situation, and the number of individuals. After the end of a fixed point observation, the objective field was around gone and the distribution point and situation of the habitation living thing kind were checked in detail also about the small living thing.

\section{RESULTS}

\section{Land use condition of the study site}

The results of the investigation of the land use condition by local exploration are shown in Fig. 3. The object area is the field block of about 34 ha, and it is the paddy field group inserted into northern Chikugo River and a southern place of residence. A small settlement exists also in the study site and the irrigation and drainage canal is crossing from the east to the west. Main

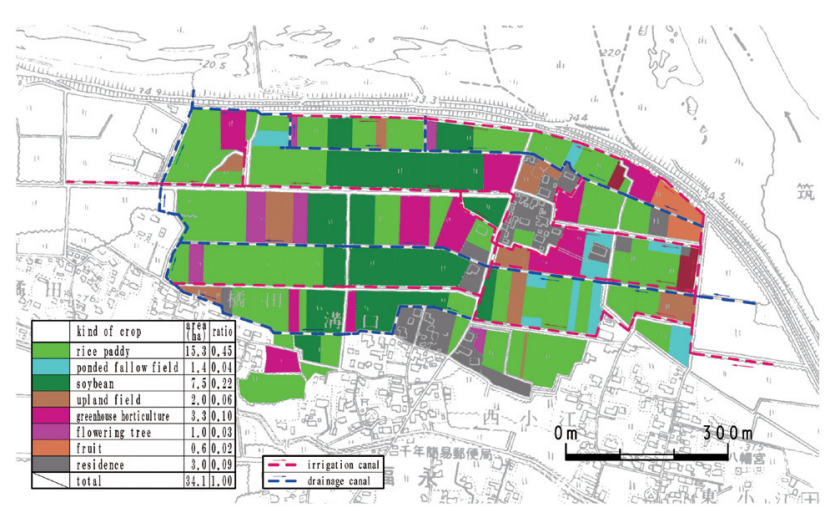

Fig. 3. Land use condition of the investigation area. crop is paddy rice, $45 \%$ of the object areas are formed, and when it restricts only to farmland, area corresponds to $50 \%$. The next has many soybeans and they occupy $22 \%$. The soybean is collected and grown over the west side in the object area, from this, it is considered that group crop rotation is carried out. Neither an abandoned cultivated land nor desolation farmland exists in the object area, but the farmland which nothing is growing is plowed or kept ponded. Many ponded fallow fields on the east side of the object area are distributed. Otherwise, the greenhouse which is growing garden plants and vegetables, such as strawberries and tomatoes, occupies the object area of about 10\%. Since these will be in a upland field semipermanently, these can call them the typical feature of the land use change from the past situation.

\section{The result of ecosystem investigation}

About the result of the ecosystem investigation conducted for three paddy fields where land use conditions differ, the food pyramid which showed the distribution is shown in Fig. 4.

About dragonflies, although the wandering Glider Pantala flavescens was observed in every cultivated land, the number of individuals changed greatly with land use conditions. Especially, extremely many dragonflies were coming flying compared with other cultivated lands, and, as for copulation and ovipositional behavior, the ponded fallow field was observed. As for the birds in a paddy field area which are high order consumers, the little egret Egretta garzetta was observed in the paddy field and the ponded fallow field. In the ponded fallow field, there were most numbers of individuals and they were observed for a long time. Moreover, the Moorthen Gallinula chloropus which said to be very cautious was also observed in the ponded fallow field. In the soybean field, crossing of the tree sparrow Passer montanus was only observed. It is guessed that upland field is not a relay point of birds.

In distribution investigation of the living thing by circumference exploration, habitation of amphibians, such as a frog, and minute living things, such as a water flea, was observed in the paddy rice field and the ponded fallow field. About the soybean field, it was deficient in habitation of the living thing which is the food of birds or Insects. As for the plant habitation situation, the grass weed belonging to Poaceae was observed by the levee in any cultivated land. The habitation of weeds was not observed on the cultivated land side, including the ponded fallow field.

Also in this observation, it was observed that the ponded fallow field has a very high function as a habitat of a living thing. When the comparison of completeness of an ecosystem, as shown in Fig. 4, it turns out that a food web develops in order of upland, paddy rice, and ponded fallow field. Especially in the ponded fallow field, the food web is formed completely.

In the viewpoint of planting program, paddy rice has the adaptability as ecology space with it in contrast with upland field crops being unsuitable for ecosystem. Since 


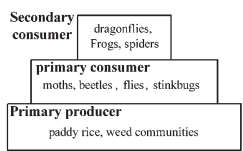

No.1 (paddy rice field)

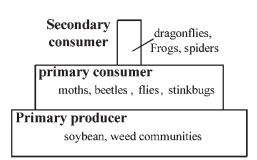

No.2 (upland field)

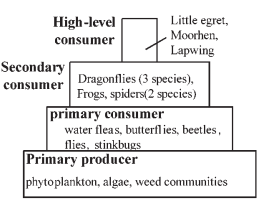

No. 3 (ponded fallow field)
Fig. 4. The food pyramid by the result of ecosystem investigation.

there were most living thing numbers of individuals observed in the ponded fallow field, the field which is not grown at all, In other words, there is no production activity, is expected to be more suitable as a native habitat of a living thing. As other different factors, it is a water surface area in the paddy rice and the ponded fallow field. When paddy rice becomes in the second half of growth, the field surface is covered by the paddy itself. On the other hand, in the ponded fallow field, a fixed quantity of water is flowing regularly, and the land side is always the water surface through a period. The ratio of the water surface area to farmland area is considered to be one of main factor in ecosystem formation.

\section{DISCUSSION}

Land use condition suitable for ecosystem network

When considering preservation of the natural environment of a rural area, it is required to build the ecosystem network which it not only generates a partial habitat, but covers a wide area. For that purpose, it is desirable to form the ecosystem corridor which made the dotted colony join. Therefore, it is necessary to examine the land use environment where the living thing with a wide behavior range can come and go between colonies. The more the behavior range of birds which are high order consumers in a paddy area becomes large, the more it can be said that the various ecology space of the area is formed.

From results of this investigation, the ponded fallow field serves as a part of the feeding and resting area of a little egret, which uses small animals, such as small fish and a frog, as the staple food, and it was observed that it is an important move base of a little egret. Then, from the land use condition map, the behavior range of the little egret in the object area is predicted.

About distribution of the behavior range and colony of herons, habitation investigation is conducted in various places (Igarashi, 1996; Shirai, 1999; Sasaki, 2001). From these reports, when a little egret performed predation activity, the flight distance in one-time flying was assumed to be $300 \mathrm{~m}$. Then, as the moving area in the once of a little egret, the circle centering on a fallow field is illustrated on the map of land use condition (Fig. 5). In the eastern part in the objective area, the several ponded fallow fields are distributed in a range circle, and active movement of little egret is expected. On the other hand, since there is no place used as a relay base of movement between western ponded fallow fields, it is expected that the behavior range area of a little egret is

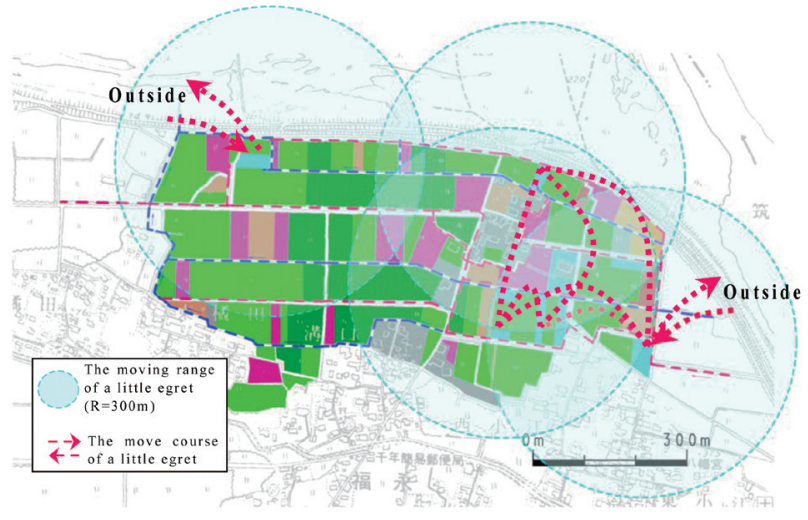

Fig. 5. The moving projection figure of the little egret which made the ponded fallow field the base.

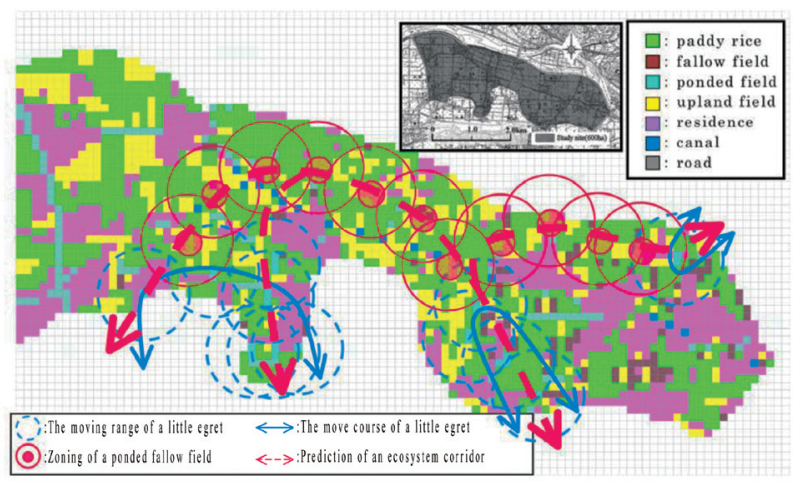

Fig. 6. Schematic view of zoning using moving prediction of the little egret.

divided. Therefore, in order to form an ecosystem network in the object area, it is thought desirable to create one ponded fallow field in the central part.

Furthermore, application is tried for ecosystem network formation prediction in such a farm block unit to the land use plan zoning in a large area. Fig. 6 shows the land use condition of about 600 ha including the investigation area by a $50 \mathrm{~m}$ mesh, and the light-blue mesh shows the ponded fallow field (Anan et al., 2007(a)). When the prediction circles of the movement of the little egret are plotted to this mesh figure, as the blue line in a figure showed, it turns out that the behavior ranges of the little egret are divided to three farm blocks. In order to form a wide range ecosystem corridor in the study site, it is one way to establish the land use plan to which a little egret can come and go these three farm blocks. The corridor line which connects three farm blocks is drawn and zoning of the prediction circle is executed along with a line. As a result, becoming a land use plan effective for formation of various ecosystem space is expected by newly establishing a ponded fallow fields in the central part of the red circle shown in Fig. 6 .

Correlation of land use condition and multifunctionality of paddy fields

In order to evaluate the multifunctionality according 


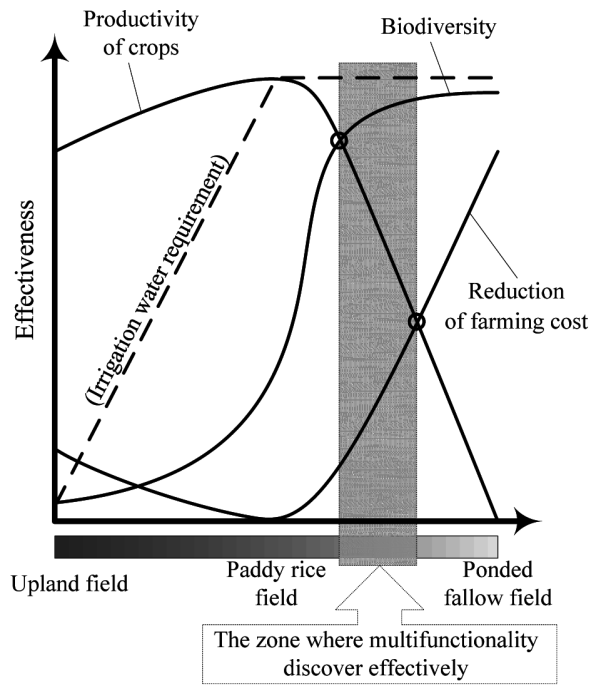

Fig. 7. The correlation diagram of the land use condition and multifunctionality of paddy fields.

to the land use condition of the paddy field in an object area, the correlation diagram showing in Fig. 7 is defined. Fig. 7 is a scatter chart which set the horizontal axis as the land use condition and the vertical axis as the evaluation value of the multifunctionality of the paddy field. It indicates by unitary about biodiversity, productivity of crops, and reduction of farming cost among the multifunctionaly effects considered to change with a land use condition. From Fig. 7, each effect in the land use condition of the paddy field becomes understanding visually. And the land use form between the intersection of biodiversity and productivity of crops and intersection of productivity of crops and reduction of farming cost, is considered as a zone which multifunctionality discover effectively. In this study, creation of this correlation diagram in the object area is tried using the farming situation, the statistics value,and the result of ecosystem investigation of the object area.

Biodiversity can be expressed the logistic curve as the following equation.

$$
n_{e}=\frac{N}{1+c \cdot \exp (-\tau)}
$$

Where $n_{e}$ is the number of individuals, $N$ is the upper limit of $n_{e}, \tau$ is the function of the environmental factor that affects the number of individuals and $c$ is a constant parameter. A logistic curve function is a correction type of an exponential function, and is one of the leading formulas as a growth curve. Although the number of individuals of a living thing increases exponentially, it is limited and reaches saturation someday. The form of a logistic curve is approximated to the rise curve peculiar to such living things, and it is applied also to the water quality model which influences plant growth (Anan et al., 2007(b), Yuge et al., 2007).

According to the result of ecosystem investigation in this study, the land use condition with the highest ecosystem preservation function is a ponded fallow field, and the tendency which develops the function in order of an upland field, a paddy field, and a ponded fallow field is shown. In this study, $n_{e}$ uses the number of the living thing kinds as the value expressing biodiversity. $\tau$ is taken as the function which shows a land use condition, has looked for a function type with high conformity, by comparison of results of the investigation and the model calculated value. As a result, the model curve at the time of giving the quadratic function expression which makes a variable the rate of an area ratio of a land use condition by $\tau$ was considered to approximate well with results of the investigation. Therefore, the valuation modeling of biodiversity is expressed like the following equation, and the model parameters are determined.

$$
n_{e}=\frac{N}{1+c \cdot \exp \left\{-\left(a_{1} x^{2}+a_{2} x+a_{3}\right)\right\}}
$$

Where $x$ is the rate of the area ratio of land use condition (In the case of upland field, $x$ is set to -1 , in the case of paddy rice, $x$ is set to 0 , and in the case of ponded fallow field, $x$ is set to 1.), $a_{1}, a_{2}$, and $a_{3}$ are parameters. Each parameters and $N$ which is upper limit of $n_{e}$ are searched by the SCE-UA method so that an error of the calculated value and results of the investigation might become small.

On the other hand, productivity of crops can be expressed the following equation.

$$
E p=\Sigma\left(S G_{i} \cdot Y G_{i}-S P_{i} \cdot Y P_{i}\right)
$$

Where $E p$ is productivity of crops, $S G_{i}$ is the present planted area of crops, $Y G_{i}$ is present yield of crops, $S P_{i}$ is the plan planted area of crops and $Y P_{i}$ is plan yield of clops.

In a paddy field, yield of rice paddy is large, and productivity of rice is the highest in all crops. And although a paddy rice field and a upland field have a function of crop production, there is nothing to a ponded fallow field. In order to evaluate these, the productivity of crop which makes a planted area ratio a variable about paddy rice and a soybean using the average yield and the average unit price in 2006 of the study site is calculated.

Furthermore, reduction of farming cost can be expressed the following equation.

$$
\operatorname{Er}=(C G-C P) \cdot A P
$$

Where $E r$ is reduction of farming cost, $C G$ is present cost per unit area, $C P$ is plan cost per unit area and $A P$ is planted area of crops. Although cost of paddy rice is comparatively high, since there are no farming activities, cost is hardly generated in a ponded fallow field.

The farming cost classified by crops integrates annual cost, which is the sum of machine cost and agricultural-work wages, based on the cultivation calendar in the study site. And the farming cost per 1 ha which makes a planted area ratio a variable is calculated, and it is made a reciprocal.

The effect calculation result in the object area is shown in Fig. 8. As it is shown in the result, although the effect of biodiversity is small in the upland field and 


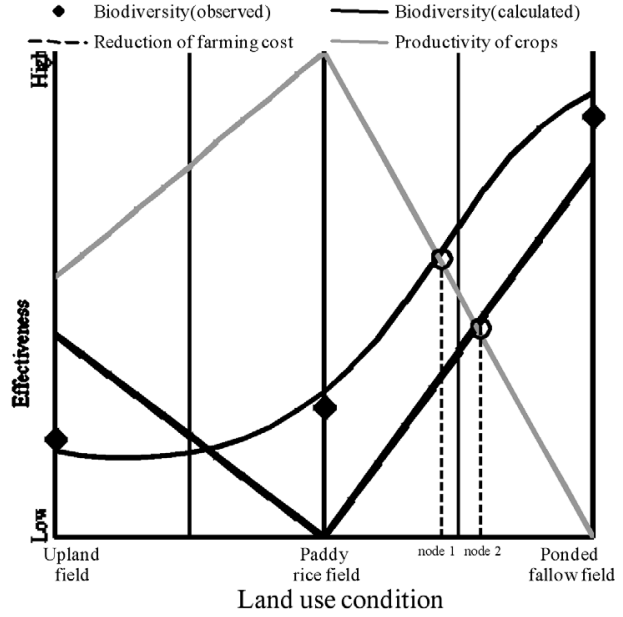

Fig. 8. The correlation diagram of multifunctionality in the object area.

Table 1. The ratio of the land use area for the optimum multifunctionality in the correlation diagram

\begin{tabular}{ccc}
\hline \multirow{2}{*}{ node } & \multicolumn{2}{c}{ The area ratio } \\
\cline { 2 - 3 } & Paddy rice field & Ponded fallow field \\
\hline 1 & 0.58 & 0.42 \\
2 & 0.43 & 0.57 \\
\hline
\end{tabular}

the rice paddy field, it becomes high abruptly as the area rate of the ponded fallow field becomes large. Productivity of crops descends with a peak of paddy rice with large yield, and which is 0 in the ponded fallow field. On the contrary, in paddy rice with much the farming work and water management work, reduction of farming cost becomes the smallest, and when the area ratio of ponded fallow field is $100 \%$, the reduction serves as the maximum. The section of the intersection (node 1) of the curve of biodiversity and the straight line of productivity of crops, and the intersection (node 2) of the straight line of productivity of crops and reduction of farming cost, is considered to be the section which can discover the effect of biodiversity, being compatible in productivity of crops and reduction of farming cost. As a result of calculating each intersection, the area ratio of a land use condition becomes as it is shown in Table $\mathbf{1}$. Therefore, the land use condition with which multifunctionality is effectively exhibited in the object area was presumed from $58 \%$ to $43 \%$ of paddy rice field at the rate of the area ratio that it was $57 \%$ from $42 \%$ of ponded fallow field.

\section{REFERENCES}

Anan, M., K. Yuge, Y. Nakano, T. Funakoshi and T. Haraguchi 2004 The relationship between water intake rates, paddy ponding depth, and farmers' water management techniques, Paddy and Water Environment, 2(1): 11-18

Anan, M., K. Yuge, Y. Nakano, S. K. Saptomo and T. Haraguchi 2007(a) Quantification of the effect of rice paddy area changes on recharging groundwater, Paddy and Water Environment, 5(1): 41-44

Anan, M., K. Yuge, K. Oogushi and Y. Nakano 2007(b) Evaluation of removal nutrient rich salts by aquatic plants using a logistics curve, Sci. Bull. Fac. Agr., Kyushu Univ., 62(1): $83-90$

Anan, M., Y. Oohira, K. Yuge and Y. Nakano 2007(c) Evaluation of the paddy irrigation effect on the preservation of ecosystem, Sci. Bull. Fac. Agr., Kyushu Univ., 62(1): 91-100

Igarashi, H. 1996 Communal roosting of the Night Heron Nycticorax nycticorax, Strix, 14: 81-94

Sasaki, M. 2001 Distribution of breeding colonies of herons and egrets and their protection in Kyoto Prefecture, Strix, 19: $149-160$

Shirai, T. 2001 Breeding biology of Grey Herons Ardea cinerea in the Tama river, Strix, 17: 85-91

Yuge, K., M. Anan, Y. Oohira and Y. Nakano 2007 Development of the water quality improvement system using water hyacinth for nitrogen removal, WATER SCIENCE, 51(4): 45-55 